\title{
Chapter 6 \\ Geotechnical Approaches to Disaster Risk Reduction in Japan and Vietnam
}

\author{
Kazuya Yasuhara and Satoshi Murakami
}

\subsection{Introduction}

One of the factors responsible for the increased severity of disasters in recent years is overlapping events that are caused by a combination of climate change- and climate change-non-associated events. These compound disasters are common in Japan and Vietnam. This study attempts to explore ways in which to increase resilience against the risk of disasters, particularly in cases where residents encounter such compound disasters, in Japan and Vietnam.

\subsection{Importance of Compound Disasters}

Compound disasters require special attention because they magnify the extent of loss and damage. Figure 6.1a shows the characteristics of compound disasters. Typically, compound disasters have the following characteristics: (i) a second natural disaster occurs immediately before or after a major disaster, generating catastrophic consequences; (ii) damage is compounded through the combination of the natural disaster with a vulnerable natural background and/or human and social situations (see Fig. 6.1b); and (iii) the psychological aftermath amplifies the damage. This classification corresponds well with that proposed by Kokusho (2005).

\footnotetext{
K. Yasuhara $(\square)$

Global and Local Environment Co-creation Institute, Ibaraki University, Ibaraki, Japan e-mail: kazuya.yasuhara.0927@vc.ibaraki.ac.jp

S. Murakami

Faculty of Engineering, Fukuoka University, Fukuoka, Japan
} 


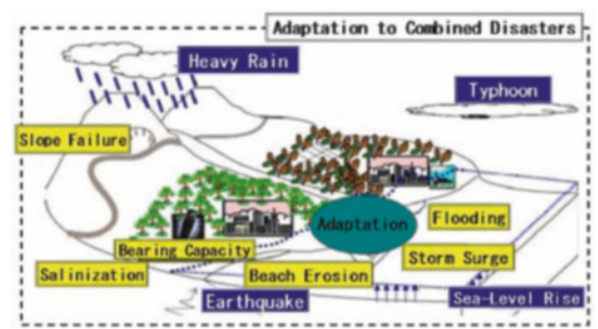

(a) Disasters are caused by multiple events

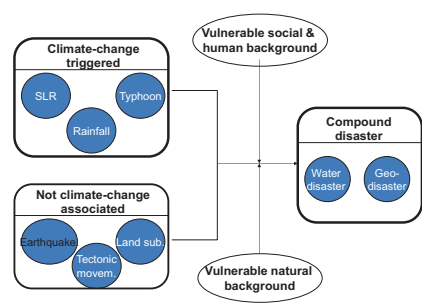

(b) Events and background associated with compound disasters

Fig. 6.1 Backgrounds of compound natural disasters (Yasuhara 2016) (a) Disasters are caused by multiple events (b) Events and background associated with compound disasters

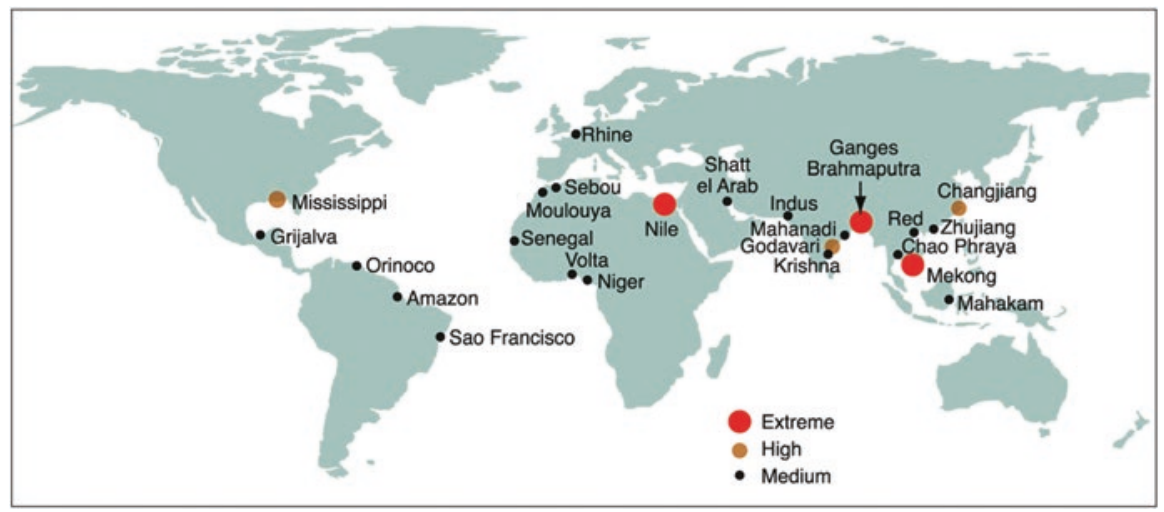

Fig. 6.2 Relative vulnerability of coastal deltas to sea-level rise (IPCC 2007)

\subsubsection{Compound Disasters Related to Sea Level Rise (SLR)}

This study describes the impacts of the compound effect of sea level rise (SLR) and land subsidence, which is a typical example of compound disaster related to climate change.

Figure 6.2 shows the location of major river deltas in the world, including the three largest deltas which are the Nile, Ganges, and Mekong river deltas (IPCC 2007). These river deltas have been designated in IPCC as extremely vulnerable coastal deltas.

Maruyama and Mimura (2010) conducted numerical analyses of the effects of SLR on inundation levels that can be expected at the end of the twenty-first century. Their results, which assume a scenario in which no adaptation measures have been put in place, showed that extensive areas in Asian regions will be inundated due to SLR.

The relative vulnerability shown in Fig. 6.3 does not consider the combined effect of SLR with land subsidence. To resolve this issue, the locations likely to 
Fig. 6.3 Predicted areas (red) of inundation (after Maruyama and Mimura 2010; Mimura 2013)
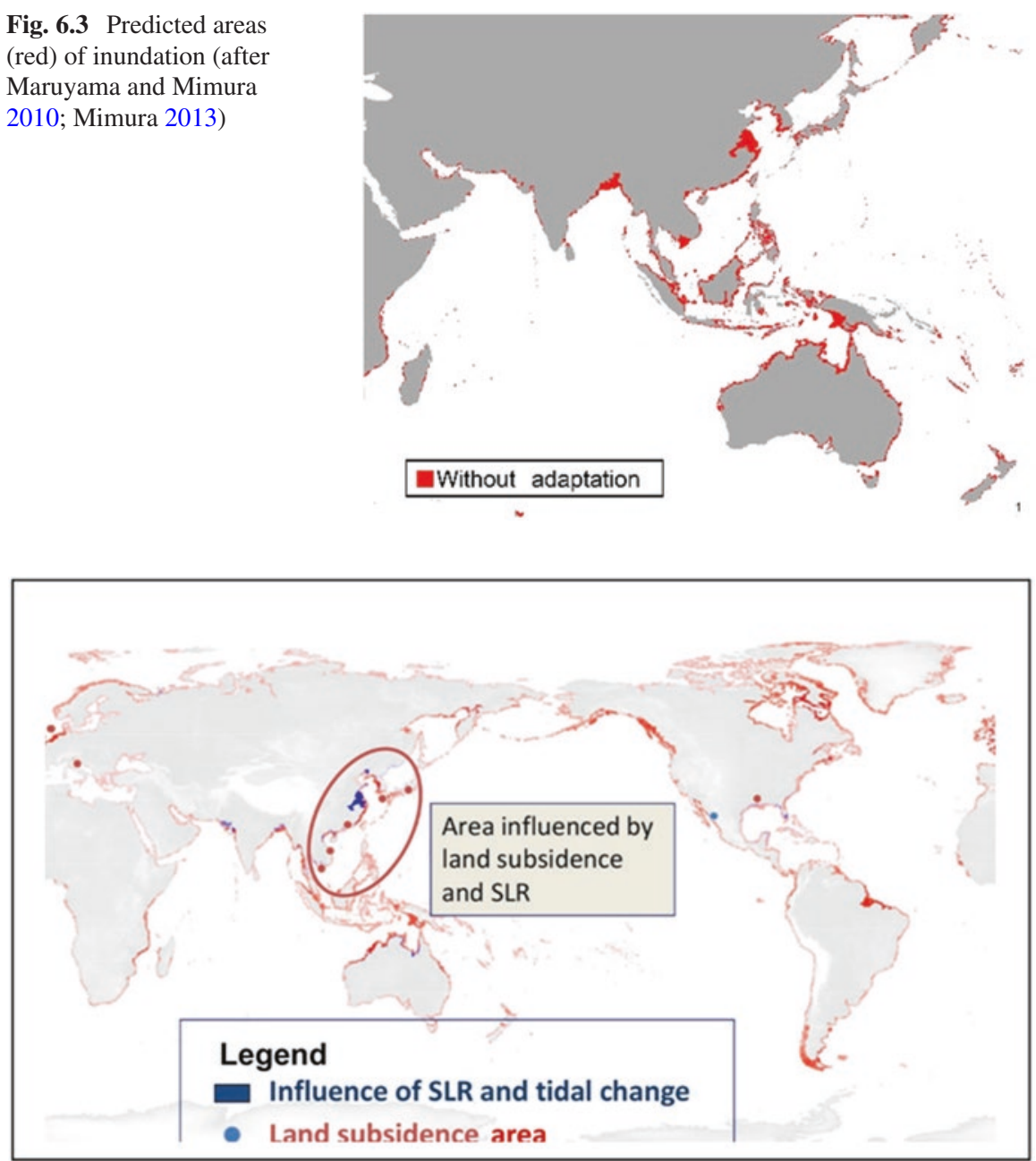

Fig. 6.4 Inundated areas obtained by combining SLR and tidal change data with land subsidence (from Maruyama and Mimura 2010)

experience severe land subsidence are shown in Fig. 6.4. The figure shows the inundated areas obtained by assuming a sea-level rise of $88 \mathrm{~cm}$ by the end of the twentyfirst century under a A1B scenario, as described in the Special Report on Emissions Scenarios (SRES) (IPCC 2007). Figure 6.3 shows areas in Southeast Asia that are at risk from land subsidence and SLR. The combined effect (named relative SLR in Fig. 6.5) of land subsidence and SLR is expected to increase the relative SLR, as shown in Fig. 6.4, which in turn increases inundation.

Therefore, precise predictions of time-dependent variations of SLR and land subsidence should be estimated, at least from the present to 2100. Settlement vs. elapsed time relations are predicted using the procedure described in Murakami 
Fig. 6.5 Definition of relative sea-level rise (Murakami and Yasuhara 2011; Yasuhara et al. 2015)
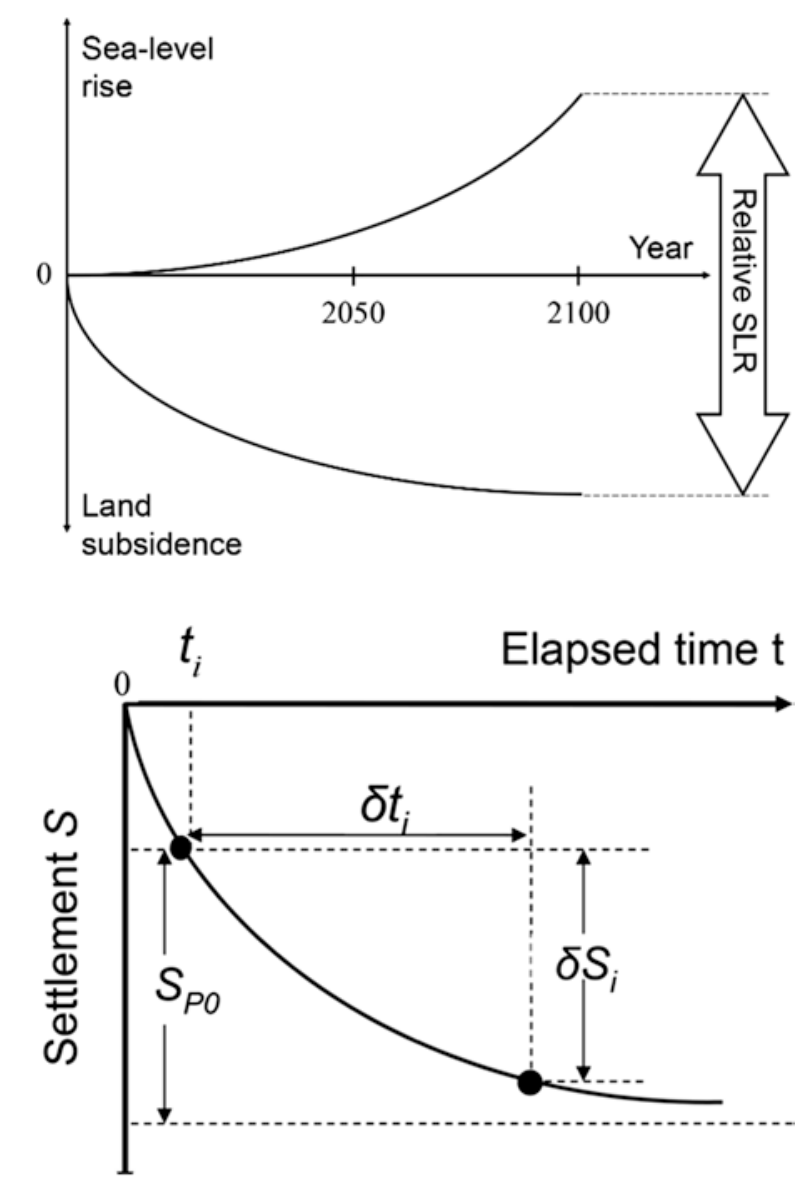

Fig. 6.6 Procedure for estimating observationbased predictions of land subsidence (Murakami et al. 2006; Murakami and Yasuhara 2011; Yasuhara et al. 2015)

et al. (2006) and shown in Fig. 6.6. Measurements of settlement are required for as many locations as possible (see Murakami et al. 2006).

The following equation is adopted to estimate the observation-based predictions of land subsidence (Murakami et al. 2006).

$$
\delta S_{i}=S_{P 0}\left\{1-\exp \left(-C_{R} \delta t_{i}\right)\right\}
$$

where, $S_{p o}$ and $C_{R}$ are parameters statistically determined using measured data at each location. 


\subsubsection{Case Study: Mekong Delta, Vietnam}

Similar to a case study conducted in the Chao Phraya Delta, Thailand, by Murakami et al. (2006), an attempt was made by Kawase et al. (2012) to predict the effects of sea-level rise and land subsidence in the Mekong Delta in Vietnam, although available data for land subsidence was insufficient and not reliable.

Land subsidence is known to have taken place in the Mekong Delta for many years (e.g, Karlsrud and Vangelsten 2017), but the manner and extent of settlement in the region remain unknown. Here the authors quantitatively describe the present and future situations of land subsidence in the Mekong Delta.

Interferometry Synthetic Aperture Radar (InSAR) was used to investigate land subsidence in the Mekong Delta. Computer software (SIGMA-SAR Cloud Platform) is useful for analyzing the variations in ground surface level caused by land subsidence over time (Murakami et al. 2006). Data for the InSAR dataset were obtained from JERS-1 image data received from December 28, 1993 through January 1, 1997. The data were modified to adapt to the SRTM3 (Shuttle Radar Topography Mission, Ver.3) and were used to produce a digital elevation model.

Land subsidence (LS) was inferred from the InSAR results and representative regions that experienced land subsidence in the Mekong Delta were identified. Finally, future settlement in the representative regions was predicted as described by Kawase et al. (2012).

The land subsidence map produced using InSAR shows that extensive settlement has occurred in Ho Chi Minh City (HCM), My Tho, and Can Tho in the period 1996-1998. The settlement rate was approximately 5-10 mm/year in HCM and around 15-20 mm/year in My Tho and Can Tho. Predictions of land subsidence in HCM, My Tho and Can Tho until 2100 appear to differ, with settlement continuing until 2100 in HMC and settlement being unlikely in My Tho and Can Tho in the future.

LS is accelerated by human activities such as excessive abstraction of groundwater. Therefore, adaptation to observed settlement over time is important as the extent of inundation damage increases due to SLR and LS. Figure 6.7 shows the following inundation scenarios in the Mekong Delta: the present, the future considering SLR, and the future considering both SLR and LS. The results emphasize the importance of considering not only the influence of SLR, but also that of land subsidence in reducing the extent of inundated areas. 


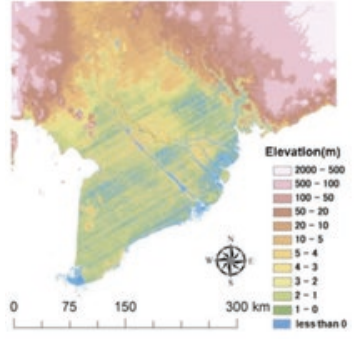

(a) Current situation

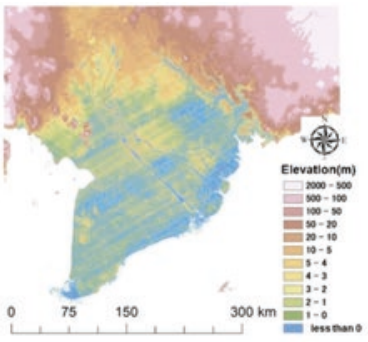

(b) Considering SLR

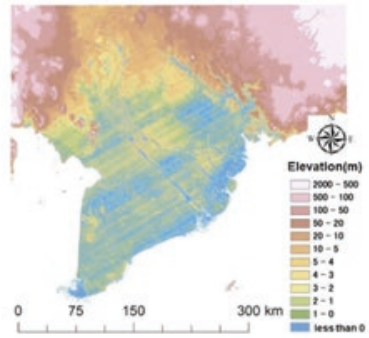

(c) Considering SLR and

LS

Fig. 6.7 Predicted inundation in Mekong Delta of Vietnam for the end of twenty-first century (Kawase et al. 2012) (a) Current situation (b) Considering SLR (c) Considering SLR and LS

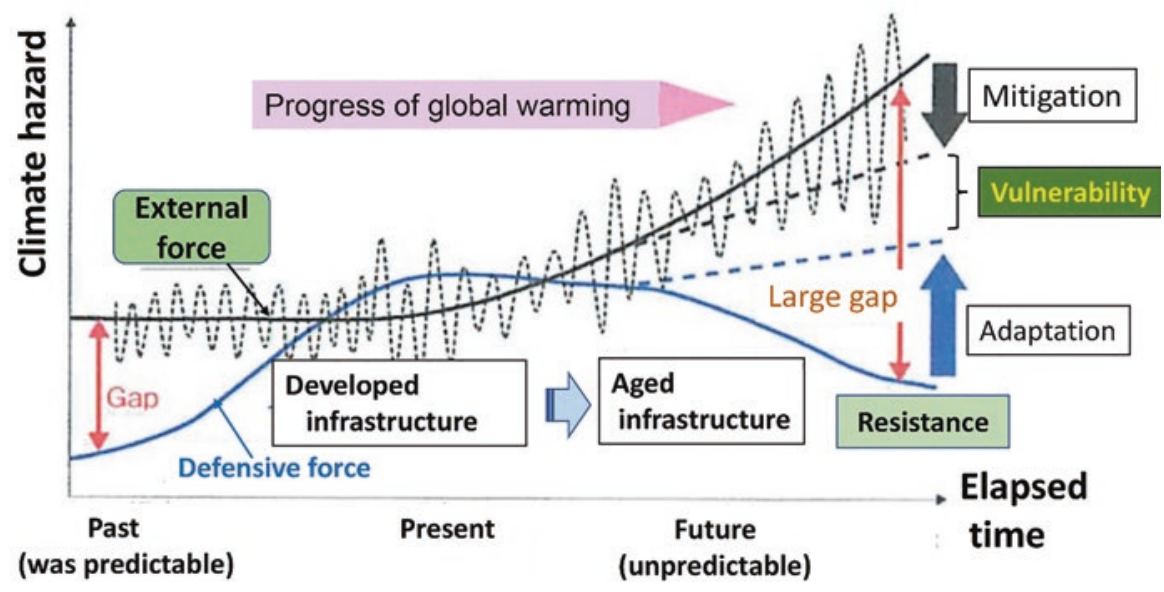

Fig. 6.8 Definition of resilience (modified from Komatsu et al. 2013)

\subsection{Resilience and the Increase Thereof}

\subsubsection{Definition of Resilience}

In the current manuscript, resilience is defined as the human potential that is capable of minimizing the gap between the external force caused by climate change and the defensive actions against climatic events, as shown in Fig. 6.8. This gap is sometimes called "vulnerability". Therefore, it can be said that resilience decreases vulnerability. 


\subsubsection{Scientific Considerations Underlying Burying the Gap Between External and Defensive Forces}

In addition to mitigation, adaptation, and combination of mitigation with adaptation, the concept of reactive to proactive responses should also be considered. For example, in a case study on flooding in 2015 in which torrential rainfall at Jyoso City in Ibaraki caused extensive damage to infrastructure and residential areas, the Kinu river dyke height was raised from $4.5 \mathrm{~m}$ to $6.0 \mathrm{~m}$. As a result, the following active measures have been proposed by The Ministry of Land, Infrastructure, Transportation and Tourism (MLIT) as mitigation measures against heavy rainfall (see Fig. 6.9).

(i) Drain work at dyke heels

(ii) Replacement of high-quality soils for avoiding differential settlement

(iii) Installation of impermeable sheet pile walls to prevent river water seepage

(iv) Surfacing work combined with concrete blocks and permeable sheets

(v) Paved top for preventing rainwater seepage

Generally, the methodology for strengthening river dykes is divided into the following steps: (1) structural reinforcement using pile installation and geosynthetics and (2) improvement of dyke soils mixed with additive materials such as cement and/or fibers (Sato et al. 2013; Yasuhara 2016). Combined adaptation is ideal, but their selection depends on government decisions. The method adopted by the MLIT can be classified as structural reinforcement (Fig. 6.9). However, the authors conducted numerical analysis to propose how dyke soils could be improved to increase overall dyke stability. Results of numerical analyses demonstrate that increased cohesion is the most important contributing factor for increased stability of sandy dykes undergoing water level rise (WLR). From a practical perspective, the results

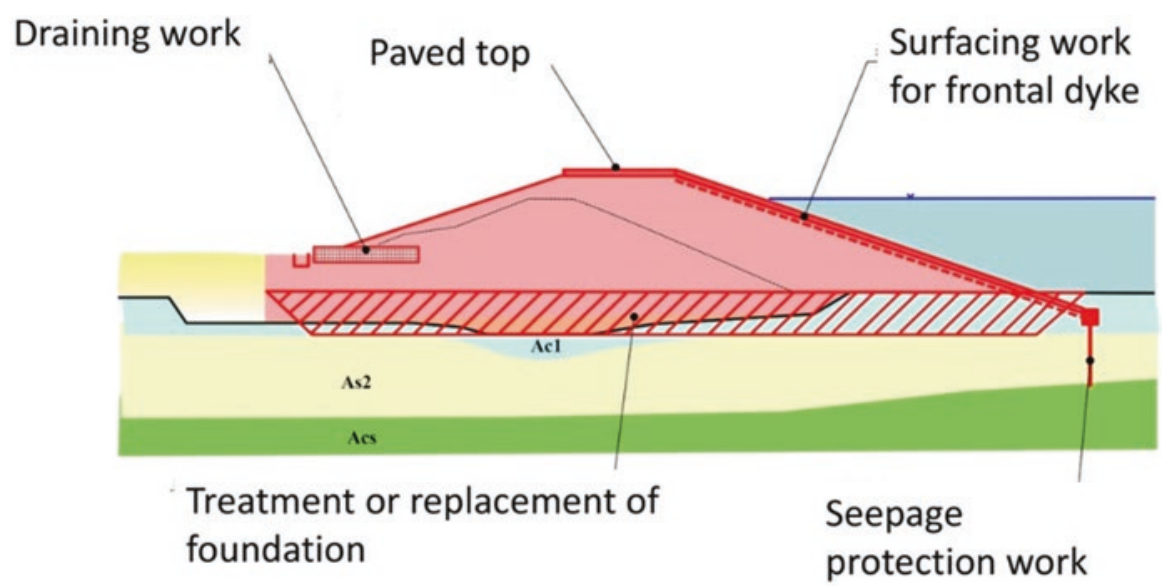

Fig. 6.9 Countermeasures for remediation of damaged river dykes (after MLIT, Japan) 
imply that adaptive measures such as adequate compaction of dyke soils at the deep layer and addition of cement to the shallow layer increase the stability of dykes undergoing WLR and overflow or overtopping. Based on the aforementioned flooding in Joso City, the following can be proposed to prepare for future extreme events (Fig. 6.10).

(i) Information collection and dissemination should be increased through cooperation with local community leaders, who are responsible for obtaining the cooperation of local residents.

(ii) Information transmission systems should be established using various tools, such as wireless-activated disaster warning systems, the internet, and the periodic patrols by public relations vehicles.

(iii) It is necessary to activate voluntary organizations for disaster prevention and to promote the adoption of information transmission systems related to flood damage. Response strategies for aged persons, handicapped persons, and foreigners in emergencies should be shared among stakeholders, such as local communities and local governments.

(iv) Early warning and early evacuation awareness need be increased, and residents' understanding of where and how they should evacuate in emergency should be reinforced.

Regarding item (i) above, important information exists in laboratory test results on the vulnerability of river dykes to erosion in Kanto, as shown in Fig. 6.11 (Sato et al. 2013). The results presented in Fig. 6.11 would have worked well for implementation as proactive adaptive measures for unexpected extreme floods if the government had focused on such measures, because they indicated which rivers and which dykes in the Kanto region were vulnerable to erosion.

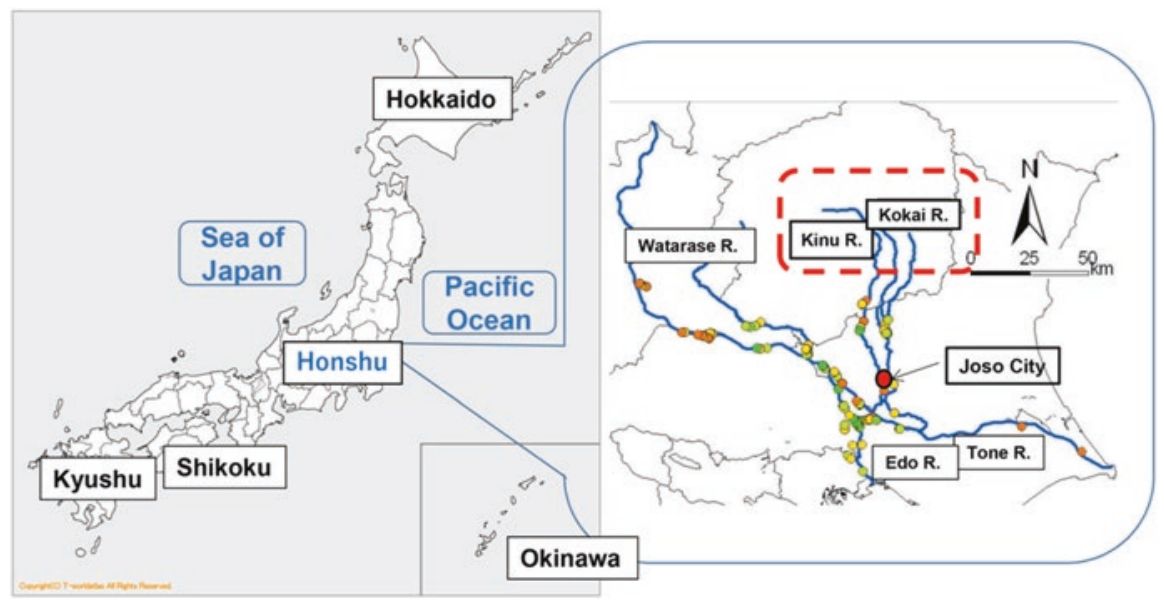

Fig. 6.10 Location of Kinu River and Joso City which suffered flood in 2015. Copyright(C) T-worldatlas All Rights Reserved 


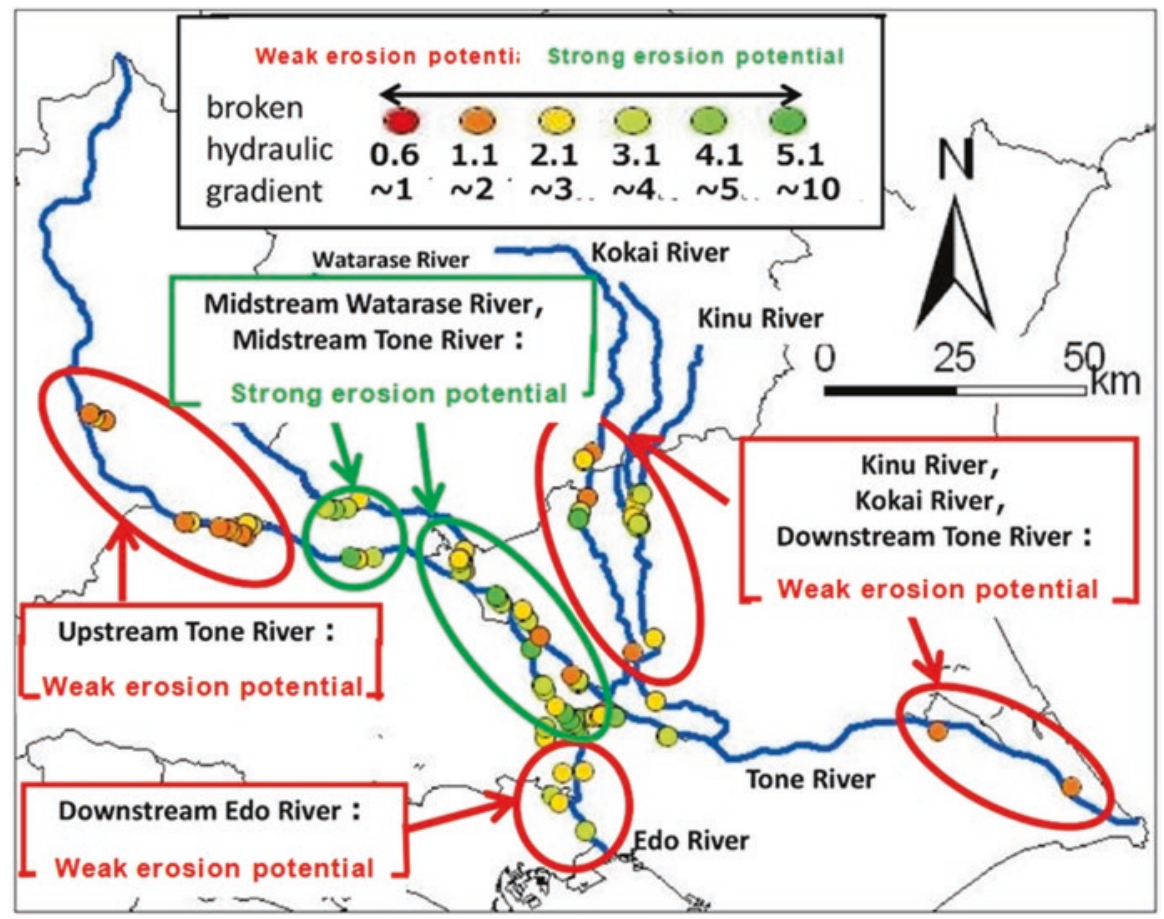

Fig. 6.11 Erosional vulnerability assessment of river dykes in the Kanto region (Sato et al. 2013)

The problem illustrated by Fig. 6.12 is who should play a role in connecting each stakeholder and their respective responsibilities. Although Fig. 6.12 shows that it is the responsibility of mass media, NGOs or NPOs, would it easy to obtain agreement among all stakeholders if a university is charged with the responsibility? This remains uncertain and is open to further discussion.

\subsection{Lessons Learned}

(i) Inundation of coastal regions undergoing a combination of SLR and LS is more serious than in regions without LS. In such regions, multiple adaptive measures should be adopted.

(ii) The concept of adaptation should be shifted from being reactive to proactive, as doing so would lead to increasing overall resilience.

(iii) Successful adaptation essentially not only requires domestic networks to connect stakeholders, but also the international networks. 


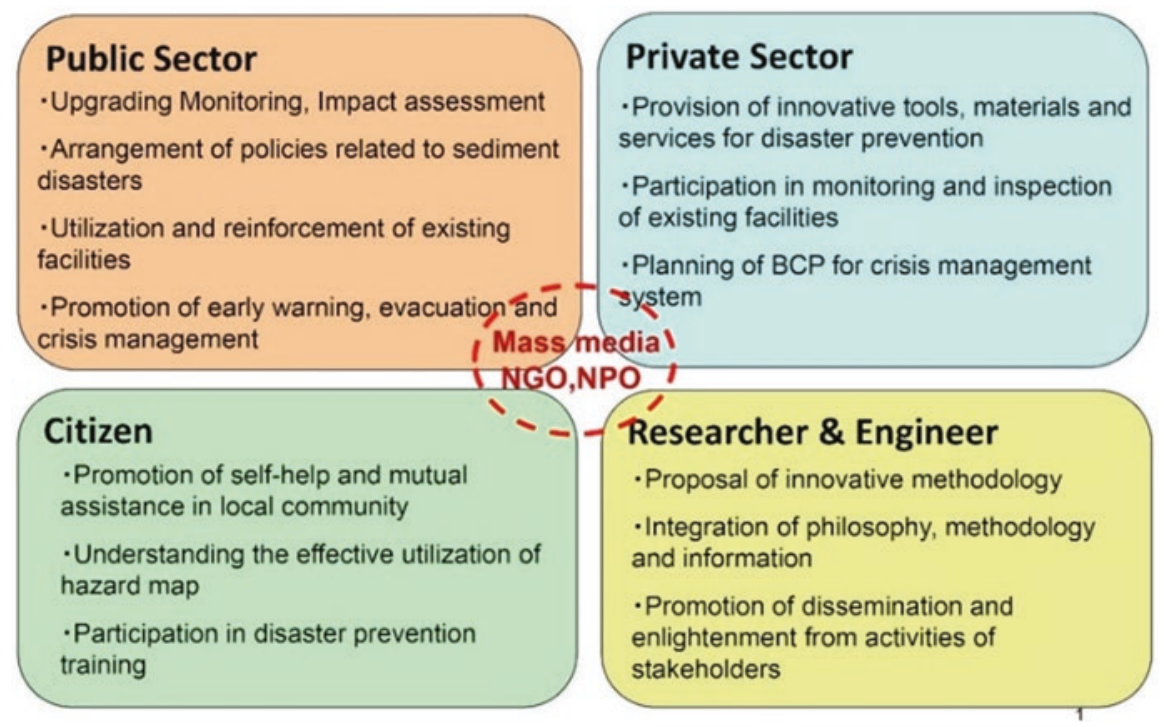

Fig. 6.12 Network for connecting stakeholders for disaster damage reduction

Acknowledgements The author expresses his sincere gratitude for financial support from a Grant-in-Aid from MEXT under the supervision of Professor Tetsuji Ito, the previous Director of Institute for Global Change Adaptation Science (ICAS), Ibaraki University, Japan.

\section{References}

Intergovernmental Panel of Climate Change (IPCC) (2007) Climate Change 2007: impacts, adaptation, and vulnerability, https://www.ipcc.ch/assessment-report/ar4/

Karlsrud K, Vangelsten BV (2017) Subsidence and land loss in the Ca Mau Province - Vietnam. Causes, consequences and mitigation options. Geotech Eng J SEAGS AGSSEA 48(1):26-32. ISSN 0046-5828

Kawase M, Murakami S, Komine H (2012) Monitoring of land subsidence in the Mekong Delta by using interferometry SAR. In: Proceedings of Awam international conference on civil engineering (AICCE'12) Geohazard information zonation (GIZ'12), Malaysia, pp 790-793

Kokusho T (2005) Extreme events in geohazards in Asia. In: Proceedings of International Conf. on Geotechnical Eng. for Disaster Mitigation \& Rehabilitation, Singapore, pp 1-20

Komatsu T, Shirai N, Tanaka M, Harasawa H, Tamura M, Yasuhara K (2013) Adaptation Philosophy and strategy against climate change-induced geo-disasters. In: Proceedings of 10th JGS Symp. on Environmental Geotechnics, Tokyo, Japan, pp 76-82

Maruyama Y, Mimura N (2010) Global assessment of climate change impacts on coastal zones with combined effects of population and economic growth. Selected Papers of Environmental Systems Research, JSCE 38:255-263. (in Japanese)

Mimura N (2013) Sea-level rise caused by climate change and its implications for society - review. Proc Jpn Acad Ser B 89(7):281-301 
Murakami S, Yasuhara K (2011) Inundation due to global warming and land subsidence in Chao Phraya Delta. In: Proceedings of the 14th Asian Regional Conference on Soil Mechanics and Geotechnical Engineering, CD-ROM, Hong Kong

Murakami S, Yasuhara K, Suzuki K, Komine H (2006) Reliable land subsidence mapping using a spatial interpolation procedure based on geo-statistics. Soils Found 46(2):123-134

Sato K, Komine H, Murakami S, Yasuhara K (2013) Experimental evaluation of seepage failure of river dykes with natural Fiber mixed with soils. Proceedings of Geotech-Hanoi, Hanoi, Vietnam, pp 1-8

Yasuhara K (2016) Geotechnical responses to natural disasters and environmental impacts in the context of climate change. In: Proceedings of International Conference on Geotechnics for Sustainable Infrastructure Development - Geotech Hanoi 2016, Phung (Editor), Hanoi, Vietnam, pp 957-981

Yasuhara K, Murakami S, Mimura N (2015) Inundation caused by sea-level rise combined with land subsidence. Geotech Eng J SEAGS AGSSEA 46(4). December 2015, ISSN 0046-5828

Open Access This chapter is licensed under the terms of the Creative Commons Attribution 4.0 International License (http://creativecommons.org/licenses/by/4.0/), which permits use, sharing, adaptation, distribution and reproduction in any medium or format, as long as you give appropriate credit to the original author(s) and the source, provide a link to the Creative Commons license and indicate if changes were made.

The images or other third party material in this chapter are included in the chapter's Creative Commons license, unless indicated otherwise in a credit line to the material. If material is not included in the chapter's Creative Commons license and your intended use is not permitted by statutory regulation or exceeds the permitted use, you will need to obtain permission directly from the copyright holder. 